\title{
Moving from Participation towards Partnership in Nursing Care
}

\author{
Irini Antoniadou1 ${ }^{1}$, Marjan Soltannia², Gunilla Björling ${ }^{3}$ and Janet Mattsson ${ }^{4 *}$ \\ ${ }^{1,2}$ Department of Perioperative Medicine and Intensive Care, Karolinska University Hospital, Sweden \\ ${ }^{3}$ Department of Health Sciences, The Swedish Red Cross University College and Department of Neurobiology, Care Sciences and Society, Sweden \\ ${ }^{4}$ Department of Health Sciences, Swedish Red Cross University College and Department of Learning, Informatics, Karolinska Institute, Sweden
}

*Corresponding author: Janet Mattsson, Department of Health Sciences, Swedish Red Cross University College and Department of Learning, Informatics, Management and Ethics, LIME, Karolinska Institute, Sweden.

Received Date: September 24, 2019

Published Date: October 22, 2019

\begin{abstract}
Background: Meeting with health care gets short before and after the operation. The difficulty at the day surgery is that preparation and information take place in close proximity to the operation. Health professionals must not only take care of the child during the medical visit, but also of the accompanying parent, too. Parents' participation in the perioperative care, sometimes unable to attend.
\end{abstract}

Aim: This study aims to investigate how parental involvement in the perioperative a process can be facilitated.

Method: A qualitative design based on observations and interviews with semi structured questions with open answers.

Results: The results conveyed involvement in the child's perioperative process in diverse ways and to a different depth. This is highlighted in the theme Allowed with the under themes Security and Being accepted. However, the theme Exclusion with the under-theme Rejection revealed a non-caring approach where no caring relation could be established. Quotes from the transcribed material are used to highlight the results.

Conclusion: The study's findings confirm earlier studies in the perspective that information is of central importance in enabling parents to be involved in the perioperative process. The results showed that parents' involvement in the perioperative process is a prerequisite for creating safety in the child and reducing concerns in connection with the operation. Parental involvement may be hindered by a conventional approach that does not include the child's perspective.

Keywords: Parent's; Perioperative nursing; Participation; Perioperative nurse; Operation

\section{Background}

Medical developments in health care have meant that surgical procedures have increased at the day surgery ward [1]. In Sweden, in 2016, as many as 31,974.14 children between the ages of 0-14 were operated in a day surgery ward [2]. When the child ends up in the hospital, the healthcare staff must also put an effort to take care of the child's parents as well. Considering the proportion of children who need surgery, there is a vast number of parents that also need to be met and cared for during their child's hospitalization. The interaction with the healthcare system is restricted to a short period before and after the surgery, with the result that parents have limited time and opportunity to prepare themselves and the child for the upcoming surgery [3]. Therefore, there is a high demand for information and participation in health care professionals who care for children and parents through the perioperative process.
As brought forward above, healthcare staff must not only care of the child during the medical visit, but also the accompanying parent. For parents, it is a stressful moment to have their child admitted to a hospital and to watch their child's suffering. But not be entirely comfortable with treatment or prognosis and the stay in an unfamiliar environment [4]. When caring for children, the holistic perspective is of central importance, the child and the parent should be seen as a whole, as the parents and the child influence each other through their interaction and communication. The parents give the child confidence and show their love. Also, parents who know their child better than anyone can explain signs of discomfort, fear or pain [4]. Most parents who accompany their child into the surgery room are worried; they know little about the procedure itself or the preparations performed [5]. The most common feelings during 
preoperative preparation are helplessness, lack of support and experience loss of control [6].

It has been shown that healthcare staff underestimates parents concerns; they perceive the parents as less anxious than parents themselves assess [7]. In order for the child to remain their trust in the parent, it is essential to support the relationship between the child and the parent [8]. It is, therefore, vital inviting parents into the child's care child, requiring interaction between nurse and parent, and preparedness in supporting their child. Even if most parents want to do this, supporting the child in preoperative preparations and the surgery room is challenging [7]. One of the challenges might be the environment that can be perceived as cold, impersonal and distant and that the possibility of being human is limited [9]. Another reason may be that parents lack knowledge about what is happening in the surgery room, which in turn increases the need for adequate information regarding the perioperative process [7].

To provide adequate information the preoperative interview is an integral part of anesthesiologist's and surgical staff. How the information is given to patients varies between hospitals. However, we must be aware that every person, regardless of age and gender, can experience a surgical intervention both physically and mentally stressful [10]. In order to reduce the child's anxiety and fear it is essential that the health care staff find aids that reduce suffering and increase the child's well-being during the care period [10]. Research [11] has shown that preoperative anxiety can be reduced if the perioperative nurse involves the parents and the child in the preoperative process.

\section{The perioperative care}

In the perioperative care, the child is someone who requires surgical care and treatment. To prepare the child and the parent for the upcoming surgery, the patient and the perioperative nurse meet in a perioperative care process [12]. The perioperative nurse may be an anaesthesia nurse or an operating nurse. Both are equally responsible for the perioperative process, and according to their competence descriptions (National Association of Operational Healthcare, \& Swedish Nursing Association, 2011), it is vital to establish a relationship with the child and their parents, based on the child's understanding and experiences concerning surgery. In addition to building a relationship and provide adequate information, the information also needs to be understandable for the parent; otherwise, insecurity can be created that is passed on through the parent to the child [13]. By meeting these requirements for information, the parents are prepared for what is going to happen and thus will be able to convey security to their child and to cooperate with the staff satisfactorily. In this way, the perioperative nurse and the parent can establish a relationship built on cooperation and trust, which enables the parent to support the child for the upcoming surgery.

In this way, a perioperative dialogue during the perioperative care becomes a prerequisite for good nursing (National Association for Anesthesia and Intensive Care \& Swedish Society of Nursing,
2012). Regardless of which profession that meets the child, their work is governed by laws and governing documents. According to the Health Care Act, care must be of good quality, easily accessible, the patient's need for security must be met, and the patient must be treated with respect for his/her self-determination and integrity [14]. A perioperative dialogue with continuity between the patient and the anaesthesia or surgical nurse offers those qualities [12]. If the dialogue is based on continuity that unfolds the patient's suffering and guards, the child's dignity concerning the surgical and anaesthetic procedure. To alleviate suffering and to create conditions for well-being is, according to [15], the core of nursing care. If the perioperative dialogue is done with different nurses, continuity might be lost as the dialogue begins in the meeting between the child and the perioperative a nurse, where the child is given time and a calm response in order to build confidence in the perioperative nurse's ability [9].

\section{Wellbeing}

As a general concept, well-being involves qualities such as contentment, joy, satisfaction and all kinds of happiness. The core of nursing care has traditionally been connected to the promotion of health and well-being [16]. Health symbolizes that a person can and do make choices that benefit health, but also that a person is oriented to time, space and person. The concept of well-being affects one's experiences and cannot be measured by others. It is one's unique experience that determines what it is that is needed to experience well-being [15]. The needs of fulfilled well-being can differ from person to person as it is a subjective experience to become satisfied. To provide opportunities for well-being means that the child must feel comfortable in the care situation, he or she experiences [17]. Suffering and well-being are not opposed to each other. Instead, one needs to acknowledge that one is suffering in order to experience well-being. It is quite possible to be in a suffering condition if, for example, it can be caused by illness, but despite this experiencing well-being [18]. However, health care might create unnecessary suffering (health care suffering) if the suffering occurs with unreflected care. Which happens when patients feel powerless and are not seen or heard by the healthcare staff. The staff should notice these feelings in the patients, and in all ways reduced. This can be achieved by creating a caring relationship where the caregiver recognizes the suffering, but still dares to stay and share the suffering with the patient. This creates a possibility for the patient to experience dignity and thus improves well-being [18].

\section{Participation}

According to [19], participation in nursing care is a complex and multifactorial concept. It means to share, to be included, engaged in a life situation, to be accepted and to have access to the necessary resources (WHO, 2001). Participation also means that all activities take place in the interaction between individuals and the surrounding context; it means that you are involved in a life situation. Being involved means being actively involved in or being involved in decisions by participating in something or having 
access to something, a feeling of being needed and experience participation [19]. According to Ygge BM, Arnetz JE [8], parental involvement can be viewed as parents' physical and mental presence, parental influence over the child's care. Participation can be viewed as active and passive in being there for their child. Parental involvement in the child's perioperative care has a calming effect on the child. Ygge and Arnetz [8] describe parents' experiences and experiences of participation in childcare as Support for one's part, the professionalism of the nurse, the work environment of the staff, and the parent's responsibility. Parents themselves expressed a need for an open dialogue with the healthcare staff as their participation in the care of their child must be based on an interaction, which means that the parents should be invited to take part in the care of the child. Some parents may feel compelled to participate in nursing, while other parents find it difficult to limit themselves and take a step back (a.a).

\section{Caring relationship}

The concept of relationship means relationship, connection, story and touch, where a relationship can never only be a relationship that is the external form but must also have one internal form that consists of connection [20]. In the children's hospital, it is not only one person that builds a relationship, but it is also the whole family. In that way the concept family-centred care is strived for. which is characterized by the relationship between caregiver and family, in which both parties engage in shared responsibility for the child's care [21]. A caring relationship can be defined as a relationship between a person as a patient and a person as a professional caregiver, in any form of care activity. A caring relationship is also described as a relationship where the career must have specific desirable characteristics. The relationship must have certain desirable characteristics and where the relationship must have specific desirable effects on the patient [20].

A caring relationship is a relationship between caregivers and the patient. The staff has professional competence, and the patient has a need for care. The patient must invite the healthcare staff into their lifeworld, and the professionals must show accessibility and openness [22]. When caring for children, care staff might need to establish a caring relationship with the parents. Since the child is not independent but dependent on the parents, the parents become an essential link to the child on several levels. The relationship between the nursing staff and the parents scaffolds a partnership between them. In turn, the partnership creates the opportunity for parents and the child to be able to express thoughts, needs and wishes. According to Mikkelsen \& Frederiksen [21], the child and the parents are provided professional support through a process of participation and partnership that is supported by ongoing communication and negotiation between the health nurses, the child and the parents. As described above, research shows that parental involvement in the perioperative process creates security and wellbeing in children but does not describe what is required in the perioperative process of creating security and wellbeing. How participation and partnerships are created needs to be further highlighted and described to reduce the insecurity and suffering of children and parents in the encounter with pediatric surgical care.

Aim

This study aims to investigate how parental involvement in the perioperative a process can be facilitated.

\section{Method}

In order to describe the parents' experiences of participation related to the perioperative nursing process, qualitative design with a phenomenological approach was chosen [23]. In order to gain access to the phenomena sought after interviews with semi-structured interviews and observation was used as a data collection source. Dalberg describes the concept phenomena "as a phenomenon as perceived, experienced or experienced by a subject" [24]. Through life-world perspectives as a point of departure, it is possible to investigate people's lifeworld in a scientific way, which means being open, compliant and allowing themselves to be surprised by the phenomenon [24]. A qualitative study highlights how individuals perceive their surroundings.

\section{Data collection}

One of the most important ways to gather data is to see and listen [25]. Which we have done in this study, as we used observations combined with interviews as data collection method. Observing and later interviewing was considered beneficial in revealing how individuals act in general and specifically in relation to how a phenomenon appears in its everyday context [26-28] raises the importance of having good knowledge about the context in which the phenomenon is sought after, to understand and follow up answers in the interview. The researcher has all extensive experience in the field. The first author who conducted the observations and following interviews has over nine years of experience working with the perioperative process, and four years of experience working with children and their parents. The first author performed interviews and observations, and all interviews were recorded on a smartphone that was password protected. All interviews were transcribed verbatim in close connection to the interview. In phenomenological research, the interview is a standard method of collecting data [23]. As described above, a nonparticipatory semi-structured observation occurred just before the interview itself, giving the observer the opportunity to become a natural part of the informant's lifeworld as well as actively listen to the informants and to observe the phenomena in its natural environment [29]. The observation consists of a description of the people who are present, the event, reactions and conversations between parents and the perioperative nurse. The emphasis on field notes was to write them as objectively as possible [30]. The following interviews were based on this observation. According to Kvale [28], the qualitative research interview is based on a belief in taking part in the respondent's world. The researcher and informant share dialogue around a topic that they both find interesting.

The interview departed from the observations with unstructured questions with open-ended response options that 
allowed the respondents to describe their experience. The role of the researcher was to provide follow-up questions so that the dialogue flowed [29]. Questions posed in the interview helped the parents to tell their experiences in their own words, while the researchers obtained information that was necessary to answer the aim of the research. The interviews were conducted during the first postoperative day, immediately after the surgical procedure. Which meant that the parents' experience was an ongoing event, and we as researchers came as close as possible to share their lifeworld during the perioperative process. The researcher conducting the observation accompanied the perioperative nurse, the child, and the parents from the perioperative ward to the operating room. When the child became anaesthetized, the researcher followed the parents back to the perioperative ward again, and they sat down together in a conversation room on the perioperative ward. Then the researcher again asked for informed consent, whether the parents would like to continue to participate in the study or not. When the researcher receives a yes, the interview begins. The study aims to gain a deeper understanding of the parents' lifeworld, their lived experiences of participation and partnership.

\section{Setting and informants}

A pediatric hospital in the middle of Sweden equipped with two-day surgical wards was selected. Suitable informants that understood spoke and read Swedish were identified through a dialogue with the perioperative nurse in charge. After that information letters were distributed, and the parents who respond positively to being included in the study were also given oral information about the study. The study includes ten parents, seven mothers and three fathers to children between 0-14 years of age in which the children were about to undergo elective surgery in outpatient surgery and where the parents planned to be present until the child has been anaesthetized. The age of the children has been targeted because it is most likely that the parents are present during anaesthesia up to the age of 14 years.

\section{Analysis}

In this study, a qualitative content analysis was used to analyze data. A manifest content analysis was used to describe and interpret the visible and apparent components of the observations. The observations in conjunction with the interview text let the researchers reach a latent content analysis that interpreted an underlying meaning $[29,31,32]$ The interviews were checked against the audio files and all material were read several times by all the authors. This was done to get acquainted with all data as a whole and to get some understanding of what it conveyed. The next step contained an amalgam of observation notes from each observation and interview text from each following interview, meaning units that were related to the aim of the study was marked in the text. The text was then condensed, and the condensed meaning units were considered as a whole and read through several times. Differences and similarities were taken into account. The author reflected on the content and tried to take into account the whole context of the text and sub-themes emerged. In the next step an abstraction was made, summarizing and deepening understanding. Themes were created through the phenomena that the sub-themes represented.

\section{Ethical aspects}

Before the observations and interviews started permission to perform the study was given by the head of the department and the ethical application (EPN 2017-1722-31-1), was approved by the Ethics Council, Karolinska Institute, Stockholm. Throughout the study, the researchers actively discussed and critically reflected how they could guard the informant's rights to privacy, health, safety and fundamental freedoms [29]. With this in mind, all informants that agreed to be observed was informed that they could stop observation at any time without questions being asked. Following ethical principles, the informants were asked again just before the interview took place if they wanted to continue to be a part of the study. The study was conducted in accordance with the Declaration of Helsinki [33] and the four basic principles of ethical research principles in human medical research in accordance with the information requirement, the consent requirement, the anonymity requirement, the utilization requirement. The informants should be informed about the study before participating in the study. The information is based on the aim of the study and the expected benefit of the study. The information should describe that participation is voluntary and the informant is, as a whole, entitled to size their collaboration in the study without causing any negative consequences for the informant [33]. All the informants that volunteered and were guaranteed confidentiality, they were given oral and written adequate information about the study and they were all informed that they could size their participation at any time during the study until the analysis had begun. They were also told that it would in no way affect future care if they chose not to participate in the study. All informants who participated signed informed consent to participation in the study. The parents had the opportunity to ask questions about the study directly to the authors in connection with the distribution of information letters, observations or interviews.

\section{Results}

The results conveyed involvement in the child's perioperative process in diverse ways and to a different depth. This is highlighted in the theme Allowed with the under themes Security and Being accepted. However, the theme Exclusion with the under-theme Rejection revealed a non-caring approach where no caring relation could be established. Quotes from the transcribed material are used to highlight the results.

\section{Allowed}

This theme highlights how allowance to care comes prior to involvement and the notion of well-being. In order to build a caring relationship, the involved persons must allow one and another to care and be cared for. In this way, involvement can be conveyed in diverse different qualitative ways building a caring relationship with external or internal connection to various extent. Routines can be used to strengthen the external relationship however to reach 
a genuinely caring relationship with the experience of well-being, both an external and an internal relationship in a complex amalgam striving towards the well-being of the child is needed, as shown below.

\section{Security}

Involvement can be understood as security of knowing what will happen, security in knowing and understanding the steps that will be taken during the procedure and security in knowing that one will be able to communicate. Security can be of a more external relationship as routines create security. However, only if it contains an option to add an internal relationship when needed or asked for. Security also means that the parent is well informed feels safe and has the ability to convey the feeling of security to the child. A security that the parent can then convey to the child. Which gives them the possibility to continue being a parent that guards their child or the parent where the child can get strength. The information that can be provided to build security and allow involvement can be information on how to prepare before surgery and a little bit of how the surgery will be conducted. The excerpt below highlights this.

"They talked to me about what would happen... what would happen after the surgery, how it would go within the surgery, and everything like that" (I, 3). "We received information at home we washed at home, then, when we came here, we got a dress that she is supposed to wear, switch on and then we were shown to a room where we can play" (I, 5). "They also called the day before and informed us. I think it was useful information. Also, I could call if there was any question if I had and it felt something too. It felt terrific" $(I, 4)$.

The excerpt above shows how routine information adds a preparedness for what is going to happen. One crucial part is that the information is directed to the individual child's parent, giving them the opportunity to be listened to or time to reflect and ask again before the surgery. A feeling of involvement can be created through a quiet and recognizable environment. In the observations, we could see that the parents acted calmer when they came out of the surgery department and experienced the environment as welcoming with colours and beautiful pictures on the wall. There are toys that the children can play with before the surgery or after the post-operative stay. In the operating room, there was a very calm and pleasant atmosphere, and the work environment was felt pleasant, which made parents feel calm and safe.

The following excerpts highlight the importance of the environment

1. "Operations department is quiet and nice and child friendly environment" (I, 1).

2. "There was a calm and pleasant atmosphere in the department and the hall. The operation team and mom had a little fun with each other. Operation nurse and anaesthesia nurse checked identification together" $(0,1)$.
3. "She is scared, afraid, she is afraid of syringes so, excellent support, how we would handle it in different ways, and her perioperative nurse concluded that she would not be given a syringe before she slept, which felt really good for her" (I,5).

4. "It was good that even then the focus on him and he would feel comfortable with all things, also the strange environment for him and me, but there were many machines and things that he still got to look at and be with, then he will be safe, ... then I will be safe" $(I, 4)$.

The excerpts above highlights how an internal relationship can be created in an instant, as there is an awareness of and responsiveness to the caring needs that will emerge during the perioperative process. This creates a caring relationship between staff and parents in a blink as there already are space for and knowledge of how to individualize nursing care. Parents also felt secure about knowing what to do after the surgery, how to get back into the daily routine, what needs the child was going to have at home and how could be given to their child.

\section{Being accepted}

Involvement can be expanded to partnership in diverse ways. Which strengthens the parents in their role as parents and gives them the opportunity to not only be with their child during the caring period, it gives them the possibility to share their child's life world. To be oriented towards their child's needs, sharing the same experience at the same time and support their child's health and well-being. A partnership can be reached when the perioperative nurse accepts and facilitates the parent's involvement in a broader sense. A caring relationship is concisely built as both an external and internal relationship between all parts of the caring encounter. Quite easy tasks such as ID control together with parents, reading to the child, singing, turning to one's child, supporting parents in doing everyday things with their child in an unknown environment, letting them dress, wash and push the bed could be such tasks. It opened for a partnership in caring for the child together.

The excerpt below highlights this.

1. "Dad tried to lunge down the baby because the baby is afraid of needles, he tries to explain to her that she does not have to be scared" $(0,3)$.

2. "Mom explained to the child about things and stuff (outfits) that were around her in the operating room. When anaesthetized, the child was in her mother's knee, breathing through a mask " $(0,7)$.

3. As shown above, accepting the parent and inviting them into the caring encounter enables the parent to participate in and share the child's life during the perioperative process. As the surgery department was a strange environment for the children, some children were stimulated by it, and others became curious about the equipment that was in the surgery room, and the parent could then share the child's situation. Other children became more worried and began to cry in the 
strange environment which the parent could share and calm down. The parent was offered to be involved in the care while sharing the child's life in an unusual situation. Parents wanted to be involved in the care and to share the routine with the perioperative nurse.

\section{Exclusion}

This theme highlights a non-caring environment where no caring relation could be established. Experience of a cold atmosphere with the awareness turned from the child toward the routines, routinised actions performed with now intention to invite the child nor the child's parents to share the actions taken. A relationship was actively prevented from occurring as an allowance to care for or being cared for from all participants in the caring situation never became established, and as a result, exclusion from care emerged. This was experienced when the perioperative a nurse was very routinely focused with a focus on her tasks and to anaesthetize the child as soon as possible. This was perceived as exclusionary and cold. The excerpts below highlights this.

\section{Rejected}

Not knowing or be prepared for what will happen creates insecurity hinders the parent to care for their child and creates a feeling of being rejected. The excerpts below highlights this. "It is just that we do not know what happens afterwards. We do not know. If she was going to take a taxi to school or things like that. She has taken time off from school this week. Will she walk with crutches, such things we do not know? We want more information" $(I, 2)$. "I kind of wonder how long time the operation is expected to take, I had no information on that, but I realize now that I have no idea if it is an hour or twenty minutes or you do not know"( $I, 6)$. "Mom is worried and stressed about the whole situation, but she tries not to show anything to the child. Mom is close to crying. A few tears flow as she leaves the room " $(0,6)$.

The excerpt above highlights how the caring relationship never evolves, hindering parents from being involved or caring for their children. Not knowing what will happen creates discomfort and mistrust. Even so, the parents try to hide their feelings for their children, being brave. Parents found it difficult at time to hand their child over to the surgery team during these conditions, which created concerns and left them feeling helpless. They found the anaesthesia and surgery to be scary and emotionally heavy in a time when they were supposed to be the safety and security for their children.

\section{Discussion}

The aim of this study is to investigate how parental involvement in the perioperative process can be facilitated. The method used was a qualitative design with interviews and observation of the phenomenon, according to [29]. The results conveyed involvement in the child's perioperative process in diverse ways and to a different depth in the theme Allowed with the under themes Security and Being accepted. Based on the results of this study, involvement and participation in the perioperative process can be strategically facilitated. We have shown how involvement can be understood and how it can evolve into a partnership with the parents of children undergoing surgical procedures during a polyclinical day surgery ward. What is more, we have shown how a non-caring approach can evolve and what harm it can cause. This is shown in the Exclusion with the under-theme Rejection revealed a non-caring approach where no caring relation could be established.

All studies have their boundaries, and it is possible that a weakness in this study is the lack of the father's perspective might have influenced the results in some way. On the other hand, it might be argued that the study reflects a common scenario in Sweden where the mothers more often than fathers accompanies the child to the hospital for planned visits. It might also be a weakness that the perioperative nurse in charge suggested which parents to ask for inclusion in the study. However, from an ethical perspective, we wanted to guard the integrity and freedom to reject inclusion in the study based on their own decision without having to meet the researchers at first hand. It may also be argued that parents who did not speak or understand Swedish were excluded on beforehand, and this might have affected the results. However, there is always chaises to be made on behalf of the researchers own limits. There are several ways of designing a qualitative study; this study was designed to include a limited number of people with as much rich data as possible.

By choosing both observations and following interviews, we arranged for triangulation of data collection and in-depth analysis as we had collected a diverse perspective of the phenomena represented in the analysis. One of the reasons for this design was the workload for the clinic; it was a stressful time in the perioperative department. To increase the credibility, the authors sought to account for all the steps taken throughout the study as clearly as possible. According to Graneheim and Lundman [31], quotes from parents' interviews were presented under each result category to allow readers to judge the validity of the result.

The results showed that it was not the information given before the surgery rather how or when it was given in relation to the surgery that opened up for involvement in the perioperative process-giving the information two days before the surgery rather than the evening before meant that the parents felt that they had control over the situation. They had time to prepare themselves and their child for what was going to happen during the day to come and in the surgical room. They were thus prepared for an opportunity to support their child, to be safe and to shoulder their parental role. Mikkelsen and Frederiksen [21] highlight this by describing how parents that receive sufficient information and are confident in a given situation can support their children and together with the staff are able to make decisions regarding the child's care. In our study, we saw that the parents have to be invited into the care of their children to have the possibility to create a caring relationship with the perioperative nurse and as such being involved in their child's care. 
Expanded preoperative information also gives parents and children the opportunity to process their fears during the hospital visit, which leads to a more realistic view of the situation. Extended information specifically for parents is found to have positive effects on both preoperative and postoperative concerns. As parent education increases well-being in postoperative care for their children, in addition to reducing preoperative concerns [34]. It was also found that involvement could become a partnership with the parents through the perioperative process. However, one prerequisite is the professional knowledge and the skills to inform in diverse ways since information needs are different in children and parents [35]. Working with perioperative dialogue in clinical work can increase the quality of both children and parents, according to Lindwall and von Post [36]. In our study, it was the knowledge of how to build and the space to build a caring relationship with both external and internal relations that provided well-being during the perioperative process. Unfortunately, we found a theme Exclusion where a non-caring approach prevailed, and no caring relation could be established. It was uncovered how parents worried about leaving the child and worried about all things that could go wrong during the operation without support or possibility to reach out to the perioperative nurse about their worries. This created a feeling of rejection and emotional stress as they feel limited and hindered to guard or care for their children. Not being able to do anything strengthened their sense of feelings of helplessness, lack of psychological support and lack of control over the situation. It is the unknown environment in the surgery department that made the parents uncomfortable.

The study also revealed that some parents did not show what they would do after the surgery, how the child would cope with everyday life. The parents felt stressed about this. Research $[5,37]$, has pointed out two stressors that create stress for parents, nursing at home (post-operative nursing at home) and not fully understanding the language. The positive thing is that it is quite manageable to prevent some of the factors described in the theme Exclusion. The four most important measures for parents to feel involved in their child's care during the hospital visit are; support from parents to their children for their own part, staff professionalism, staff responsibility and work environment [8]. The parents are guardians of their children's well-being and safety during the hospital stay, and it is our responsibility to involve them and build a partnership with them during the perioperative process. It will reflect on the child's well-being how well the perioperative nurse succeeds with the creation of a caring relationship [38-43].

\section{Implication for practice}

The results of the study can give health care professionals an increased understanding of parental involvement in the perioperative process, which can improve care and care in relation to these parents. Taking care of parents' knowledge of their children and seeing parents as a resource in perioperative care is essential knowledge for care staff [44-47]. The results can contribute to nursing science through a more in-depth picture of parental involvement in the perioperative process.

\section{Conclusion}

The study's findings confirm earlier studies in the perspective that information is of central importance in enabling parents to be involved in the perioperative process $[48,49]$. The results showed that parents' involvement in the perioperative process is a prerequisite for creating safety in the child and reducing concerns in connection with the operation. Parental involvement may be hindered by a conventional approach that does not include the child's perspective.

\section{Acknowledgement}

None.

\section{Conflict of Interest}

None.

\section{References}

1. Wennström B, Hallberg LRM, Bergh I (2008) Use of perioperative dialouges with children undergoing day surgery. J Adv Nurs 62(1): 96106.

2. Socialstyrelsen (2018) Outpatient surgery.

3. Runeson I, Proczkowska Björklund M, Idval E (2010) Ethical dilemmas before and during anaesthetic induction of young children, as described by nurse anaesthetists. J Child Health Care 14(4): 345-354.

4. Tveiten S (2000) Nursing in pediatric care. Lund: Student literature.

5. Shields L (2010) The psychosocial care of children in the perioperative area. I Shields L (Red.), Perioperative care of the child: a nursing manual. Hoboken: Wiley Blackwell.

6. Vessey JA, Bogetz MS, Caserza CL, Liu KR, Cassidy MD (1994) Parental upset associated with participation in induction of anaesthesia in children. Can Journal of Anaesth 41(4): 276-280.

7. Davidson A, Howard K, Browne W, Habre W, Lopez U (2012) Preoperative evaluation and preparation, anxiety, awareness, and behavioral change. I Gregory, GA, Andropoulos, B (Red.), Pediatric anesthesia. Hoboken: WileyBlackwell.

8. Ygge BM, Arnetz JE (2004) A Study of Parental Involvement in Pediatric Hospital Care: Implications for Clinical Practice. J Pediatr Nurs 9(3): 217-223.

9. Lindwall L, Von Post I (2008) Perioperative care: unifying theory and practice $2^{\text {nd }}(e d n$.$) , Lund: Student literature, Sweden.$

10. Panelius M, Varisto H (1989) Perioperative care teaching. Lund: Student literature, Sweden.

11. Berglund I, Eriksson E, Proczkowska Björklund M, Fridlund B (2013) Nurse anaesthetists' experiences with pre-operative anxiety. Nurs Child Young People 25(1): 28-34.

12. Lindwall L, Von Post I (2000) Perioperative care: the perioperative care process. Lund: student literature, Sweden.

13. Enskär K, Golsäter M (2014) From childhood to adolescence-the growing need for nursing care. In: F Friberg, J Öhlén (Eds.). The basics of nursing: Perspective and approach. Lund: Student literature, Sweden.

14. (1982) SFS: The Health Care Act. Stockholm: Swedish Parliament pp: 1-763.

15. Eriksson K (2000) The idea of health. Stockholm: Liber.

16. Ehnfors M, Ehrenberg A, Thorell Ekstrand I(2007) The VIPS book Stockholm: Healthcare Association.

17. Torunn Björk I, Breievne G (2007) Body and well-being. In: Jahren Kristoffersen N, Nortvedt F, Skaug EA (Eds.), Basic Nursing Part 1, Stockholm: Liber, pp: 106-136. 
18. Dahlberg K, Segersten K, Nyström M, Suserud B, Fagerberg I (2003) Understanding health care science. Lund: Student literature, Sweden.

19. Cahill J (1996) Patient participation: a concept analysis. J Adv Nurs 24(3): 561-571.

20. Björk M, Sandman L (2007) Care relationship An attempt to clarify the use of the concept. Care in the Nordic countries 27(4): 14-19.

21. Mikkelsen G, Frederiksen K (2011) Family-centred care of children in hospital-a concept analysis. J Adv Nurs 67(5): 1152-1162.

22. Dahlberg K, Segesten K (2010) Health and care: in theory and practice. $1^{\text {st }} \& 2^{\text {nd }}($ edn.), Stockholm: Nature \& Culture, Sweden.

23. Starrin B, Svensson PG (1994) Qualitative method and theory of science. Lund: Student literature, Sweden.

24. Dahlberg K (1993) Qualitative methods for care scientists. Lund: Student literature, Sweden.

25. Ely M, Anzul M (1993) Qualitative research methodology In practicecircles within circles. Lund: Student literature.

26. Benner P (1994) The tradition and skill of interpretive phenomenology in studying health, illness, and caring practices. Interpretive Phenomenology: Embodiment, Caring, and Ethics in Health and Illness. Thousand Oaks, CA: Sage.

27. Benner PE, Wrubel J (1989) The primacy of caring: stress and coping in health and illness. In: Menlo Park (Edt.), Calif: Addison-Wesley Pub Co xxii, USA.

28. Kvale S (2001) The qualitative research interview. Lund: Student literature, Sweden.

29. Polit DF, Beck CT (2012) Nursing research: generating and assessing evidence for nursing practice. Philadelphia : Wolters Kluwer Health/ Lippincott Williams \& Wilkins, USA.

30. Taylor S J, Bogdan R (1984) Introduction to qualitative research methods. New York: John Wiley \& Sons, USA

31. Graneheim UH, Lundman B (2004) Qualitative content analysis in nursing research: concepts, procedures and measures to achieve trustworthiness. Nurse Education Today 24: 105-112.

32. Dahlberg K (2014) To examine health and care. Nature \& culture: Student literature, USA.

33. World Medical Association Declaration of Helsinki (2013) Ethical principles of medical research involving human subjects. Retrieved from 2018-09-10.
34. Chan MC, Molassiotis A (2002) The effect of an educational program on the anxiety and satisfaction level of parents having present induction and visitation in a post anesthesia care unit. Paediatr Anaesth 12(2): 131-139.

35. Wisselo T, Stuart C, Muris P (2004) Providing parent with information before anastethsia: what do they really want to know? Pediatric Anastethsia 14: 299-307

36. Lindwall L, Von Post I (2005) Man in perioperative care-Anthropological and ethical reflection. Karlstad: Karlstad University.

37. Shirley PJ, Thompson N, Kenward M, Johanston G (1998) Parental anxiety before elective surgery in children. Anaesthesia 53(10): 956959

38. Granskär M, Höglund Nielsen B (2017) Applied qualitative research in the field of health care. Lund: Student literature, Sweden.

39. Hallström I, Lindberg T (2015) Pediatrisk omvårdnad. Stockholm: Liber $A B$, Sweden.

40. Hartman J (2004) Scientific thinking: from knowledge theory to method theory Lund: Student literature, Sweden.

41. Kain ZN, Mayes LC, Wang SM, Caramico LA, Krivutza DM, et al. (2000) Parental presence and a sedative premedicant for children undergoing surgery: a hierarchial study. Anesthesiology 92(4): 939-946.

42. Nationalencyklopedin (2018) Children, Parents, Motherhood, Fatherhood.

43. (2012) National Association for Anesthesia and Intensive Care \& Swedish Nurse Association. Competency description for a qualified nurse with specialist nursing degree with specialization in anesthesia care. Sweden.

44. (2011) The Swedish National Nursing Association, \& Swedish Nurses' Association Competence description for a qualified nurse with a specialist nursing degree specializing in surgical nursing.

45. Sandberg N, Elander G (1997) Pediatrics. Stockholm: Liber, Sweden.

46. (1949) SFS: Parental Code. Stockholm: Parliament pp: 1-381

47. Socialstyrelsen (2005) Skills descriptions for qualified nurses. Article number 105-111.

48. NICEF Sweden (2009) The Convention on the Rights of the Child: UN Convention on the Rights of the Child. Stockholm: UNICEF Sweden.

49. (2001) WHO International classification of functioning, disability and health (ICF). Geneva: World Health Organization. 